\title{
Skill Acquisition Theory and Its Important Concepts in SLA
}

\author{
Masumeh Taie \\ College of Foreign Languages and Literature, Science and Research Branch, Islamic Azad University, Tehran, Iran
}

\begin{abstract}
Skill Acquisition Theory is not just a theory of the development of language, rather it is a general theory of learning ranging from cognitive to psychomotor skills (Mystkowska-Wiertelak \& Pawlak, 2012). This theory, which is based on Adaptive Control of Thought model (ACT), claims that adults commence learning something through mainly explicit processes, and, through subsequent sufficient practice and exposure, proceed to implicit processes (Vanpatten \& Benati, 2010). Considering the fact that each one of the SLA theories illuminates one aspect of SLA (VanPatten \& Williams, 2007), this paper attempts to investigate this Theory and its basic constructs.
\end{abstract}

Index Terms — skill, priming, automaticity, practice, power law of practice

\section{INTRODUCTION}

Pondering over the process of language acquisition has been one of the old endeavors of human beings to solve the enigmas of second language acquisition (SLA). This endeavor which has been reified into different forms (such as, theories, framework, or models) has obsessed scholars from ancient times to modern days, from the Plato's problem to Truscott and Sharwood Smith's (2004) MOGUL. Nevertheless, though many of these ideas seem to be competing, they can be considered to be complementary. That is, like the parable about four blind men and an elephant, SLA can be considered to be like a giant elephant which can be observed by different scholars from different perspectives (VanPatten \& Williams, 2007). Therefore, each SLA theory might shed light on one aspect of SLA. Taking this point into consideration, Skill Acquisition Theory- as one of the prominent and influential SLA theories which has considered language learning to be on a par with general human learning- has been discussed in this paper with the aim of gaining a better insight into the process of SLA.

\section{LITERATURE REVIEW}

\section{A. Background}

The scientific roots of Skill Acquisition Theory can be found in different branches of psychology, which ranges from behaviorism to cognitivism and connectionism (Dekeyser \& Criado, 2013). This theory draws on Anderson's Adaptive Control of Thought (ACT) model which itself is a kind of cognitive stimulus-response theory (Ellis \& Shintani, 2013). As mentioned by Parziale \& Fischer (2009), it is a neo-Piagetian theory that amalgamates elements of both cognitive and behavioristic theories. In SLA there are a number of theories which have been devised based on models of skill acquisition in cognitive psychology. According to Chapelle (2009), this theory falls under the category of general human learning, i.e., it focuses "on language learning as a process of human learning". In other words, learning a second language in view of such theories is considered to be like learning any other skill, e.g., playing a musical instrument. Advocates of such theories consider practice to play the key role in learning.

\section{B. Basic Claim}

The basic claim of Skill Acquisition Theory, according to Dekeyser (2007b), "is that the learning of a wide variety of skills shows a remarkable similarity in development from initial representation of knowledge through initial changes in behavior to eventual fluent, spontaneous, largely effortless, and highly skilled behavior, and that this set of phenomena can be accounted for by a set of basic principles common to acquisition of all skills" (p. 97). In sum, as mentioned by Speelman (2005), skill acquisition can be considered as a specific form of learning, where learning has been defined as "the representation of information in memory concerning some environmental or cognitive event" (p. 26). Therefore, according to him, skill acquisition is a form of learning where "skilled behaviors can become routinized and even automatic under some conditions" (p.26).

In other words, this theory assigns roles for both explicit and implicit learning in SLA. And, as a general theory of learning, it claims that adults commence learning something through largely explicit processes, and with subsequent sufficient practice and exposure, move into implicit processes. Development, within this theory, entails the utilization of declarative knowledge followed by procedural knowledge, with the latter's automatization (Vanpatten \& Benati, 2010). According to Richards \& Schmidt (2010), declarative knowledge is conscious knowledge of facts, concepts or ideas that can be stored as propositions. And procedural knowledge refers to unconscious knowledge of how an activity is 
done. As elaborated by Vanpatten \& Benati (2010), using declarative knowledge involves explicit learning or processes; learners obtain rules explicitly and have some type of conscious awareness of those rules. The automatization of procedural knowledge entails implicit learning or processes; learners begin to proceduralize the explicit knowledge they own, and through situational suitable practice and use, the behavior becomes second nature.

Ellis (2009) has referred to the following features as the characteristics of explicit and implicit knowledge. Of course, it should be mentioned that still there is no unanimous agreement over such characteristics.

- "Implicit knowledge is tacit and intuitive whereas explicit knowledge is conscious" (p. 11)

- "Implicit knowledge is procedural whereas explicit knowledge is declarative" (p. 11)

-"L2 learners' procedural rules may or may not be target-like while their declarative rules are often imprecise and inaccurate" (p. 12)

-"Implicit knowledge is available through automatic processing whereas explicit knowledge ls generally accessible only through controlled processing" (p. 12)

-"Default L2 production relies on implicit knowledge, but difficulty in performing a language task may result in the learner attempting to exploit explicit knowledge" (p. 13)

- "Implicit knowledge is only evident in learners' verbal behavior whereas explicit knowledge is verbalizable" (p. 13)

-"There are limits on most learners' ability to acquire implicit knowledge whereas most explicit knowledge is learnable" (p. 14)

-"The learners L2 implicit and explicit knowledge systems are distinct" (p. 14)

-"L2 performance utilizes a combination of implicit and explicit knowledge" (p. 15)

In Pawlak's view (2011), the transformation from declarative knowledge to procedural knowledge entails qualitative and quantitative changes in the initial declarative representation. And such changes take place through automatization and restructuring, where the former refers to "speeding up the performance of a skill, reducing the error rate and inference from other tasks" and the latter to "changing the subcomponents of knowledge and the way in which they interact" (p. 13). Of course, as also mentioned later on such terms are not easy to define.

It should be mentioned that the great advantage of proceduralized knowledge over declarative knowledge is that it is available as "a ready-made chunk to be called up in its entirety each time the conditions for that behavior are met", (DeKeyser 2007b, p. 98). Moreover, Ellis \& Shintani (2013) have referred to the skill-specificity in Skill Acquisition Theory. That is, as mentioned by them, this theory predicts that the effects of instruction are skill-based. In other words, input-based and output-based instructions will benefit receptive and productive skills respectively.

\section{Important Concepts}

\section{Skill}

There are several concepts which play a key role in this theory. One such concept is skill. The definition of skill is vague. As defined by Vanpatten \& Benati (2010, p. 39) "Skill refers to ability to do rather than underlying competence or mental representation". To clarify this concept, Cornford (1996) has mentioned nine separate defining attributes of "skill" and "skilled performance" from a psychological perspective, argued to be the most valid in accounting for skill acquisition and performance by individuals. These defining attributes are:

1. skill is learned;

2. skill involves motivation, purpose and goals;

3. Schemas are prerequisite for skilled performance;

4. Skills require content and context knowledge;

5. Skills are performed and transferred in the presence of specific stimuli;

6. Skills involve problem solving relevant to the context;

7. Skill involves relative judgments with individual differences in skilled performance evident;

8. Standards of excellence are important;

9. Skill involves comparable replication;

10. Considerable periods of time are required to reach high levels of skill.

\section{Priming}

The other important concept in Skill Acquisition Theory is "priming" which, according to Trofimovich \& McDonough (2013, p. 505), "refers to a cognitive repetition phenomenon in which prior exposure to specific language forms or meaning facilitates speaker's subsequent language processing". For example, a words or structure used by a speaker will influence the comprehension and production of that word or structure by the interlocutor. Therefore, it "may underlie the interactive, communicative use of language" (Trofimovich \& McDonough, p. 505). At the same time, it can be categorized under the implicit learning since it often happens with little awareness and conscious effort on the part of language user (Trofimovich \& McDonough).

\section{Automaticity}

The other concept within this theory is automaticity. According to DeKeyser (2007a), in skill acquisition models, the learning processes which are involved in the acquisition of skills entails a transition from attentive to automatic mode. Hulstijn (2002) believes that performance fluency is the outcome of implicit learning, and a concomitant, incidental feature of implicit learning is automatization. But defining automaticization is not an easy task. As mentioned by Dekeyser (2007a, p. 4), "In the broadest sense, it refers to the whole process of knowledge change from initial 
presentation of the rule in declarative format to the final stage of fully spontaneous, effortless, fast, and errorless use of that rule, often without being aware of it anymore. In a narrower sense, it refers to the slow process of reducing error rate, reaction time, and interference with/from other tasks that takes place after proceduralization. In the most specific sense, it designates a merely quantitative change in the subcomponents of procedural knowledge to the exclusion of any qualitative change or restructuring (i.e., excluding changes in which small subcomponents make up procedural knowledge at a given stage of skill development or how they work together)." In fact, as acknowledged by Cohen, Servan-Schreiber, \& McClelland (1992), the term automaticity embodies some different phenomena that often differ from one definition to another. Nevertheless, the following core set of phenomena seem to reappear in most discussions of automaticity:

"1. an increase in speed of performance with practice following a power law

2. diminishing requirements for attention with practice, with

3. a commitment release from attentional control - or involuntariness (i.e., the involuntariness of automatic processes)

4. immunity from interference with competing processes, and

5. the requirement that practice be "consistently mapped" for these phenomena to develop." (pp. 241-242).

It should be mentioned that DeKeyser $(2007 \mathrm{c})$ has chosen the term automatized knowledge to refer to the knowledge which may still be conscious but the learner has access to it in actual communication. In Dekeyser's view, automaticity rather than being an all-or-nothing issue has degrees.

\section{Practice}

According to DeKeyser (2007b), among researchers who study skill acquisition processes there is a consensus that practice with a given task gradually decreases reaction time and error rate. Carlson (1997, as cited in DeKeyser, 2007a, p: 2) has defined practice as "repeated performance of the same (or closely similar) routines". As it can be observed, this definition is fairly vague and seems to reflect behavioristic views rather than those of cognitive psychology. DeKeyser (2007a) believes this is not what Carlson means. Therefore, he has found the definition by Newell and Rosenbloom (1981, as cited in DeKeyser, 2007a) to be more precise, i.e., "Practice is the subclass of learning that deals only with improving performance on a task that can already be successfully performed" (p. 2). Practice which is required for learning in skill Acquisition Theory, according to Dekeyser (2007b) should be meaningful. In fact, Dekeyser has questioned the utility of mechanical drills by considering them to provide just language-like behavior rather than language behavior.

\section{Power law of practice}

Newell \& Rosenbloom (1981) have studied practice and its following performance improvements both theoretically and experimentally. On the theoretical side, they have formulated 'chunking theory of learning' which is rooted in cognitive psychology. And on experimental side, they have argued that a single law, i.e., the "log-log linear learning law" or the "power law of practice" describes all of the practice data. According to Newell \& Rosenbloom , this ubiquitous quantitative law of practice, states "plotting the logarithm of the time to perform a task against the logarithm of the trial number always yields a straight line, more or less".(p. 1)

Hulstijn (2002) believes that automatization conforms to the power law of learning both in what Gupta \& Dell (1999) name "repetition priming" and "skill learning". The former occurs when we process identical stimuli over and over again (i.e., the same word is processed the many times), whereas the latter occurs when we process stimuli which (1) vary in some respect at the surface, but (2) share similarities or regularities at an underlying level of structure.

\section{Theories}

Speelman (2005) believes that there are two groups of theories regarding skill acquisition. The first group holds that skill acquisition results from a process of strategy refinement. This is the idea underlying the theories of Crossman, Anderson (ACT-R), Newell et al. (SOAR), MacKay, and some connectionist theories. And the other group holds that skilled performance is the results of improved memory retrieval. This idea can be found in the theories of Logan (Instance theory) and Palmeri (EBRW).

\section{Adaptive control of thought model (ACT)}

According to Vanpatten \& Benati (2010), Adaptive Control of Thought (ACT) model, developed by John Anderson, is the most well-known models of skill-based theories. Anderson (1982) proposed a framework for skill acquisition including two major stages in the development of a cognitive skill, i.e., declarative and procedural stage. In this framework "facts are encoded in a propositional network and procedures are encoded as productions" (Anderson, 1982, p. 369). According to Vanpatten \& Benati (2010, p. 33), "Within this theory, development involves the use of declarative knowledge followed by procedural knowledge, with the latter's automatization." Therefore, SLA is conceived to be a progression through three stages, declarative, procedural, and autonomous. These three stages resembles the three stages of cognitive, associative, and autonomous stage which Fitts (1964, as cited in Taatgen, 2002) posits for skill acquisition. Taatgen (2002) has linked Anderson and Fitts stages by saying "In the cognitive stage knowledge is declarative and needs to be interpreted. Interpreting knowledge is slow, and may lead to errors if the relevant knowledge cannot be retrieved at the right time. Procedural knowledge on the other hand is compiled and therefore fast and free of errors, and can be associated with the autonomous stage. The associate stage is an in-between stage, during which part of the knowledge is declarative and another part compiled." (p. 103) 


\section{Ackerman's model}

Ackerman (1988) theory posits that there are different abilities underlying performance at consecutive stages of skill acquisition. In phase 1, general ability measures (e.g., abstract reasoning) underlie performance. With the formation of the production systems for the consistent features of performance, the influence of these factors decreases, and perceptual speed abilities appear as important predictors of performance in Phase 2. Eventually, performance is determined mainly by non-cognitive psychomotor abilities in Phase 3.

\section{E. Criticisms}

\section{Weak points}

Like many SLA theories, the problem of the lack of an operational definition undermines the Skill Acquisition Theory. In fact, though some attempts have been made, still there is no unanimously agreed-upon operational definition for the basic concepts in this theory such as skill, practice, or automatization.

Moreover, Skill Acquisition Theory provides a rationale for the strong-interface position (Ellis \& Shintani, 2013). And this "position holds that explicit knowledge can be transformed into implicit knowledge through the process of automatization, which is a consequence of practice" (Richards \& Schmidt, 2010, p. 292). Therefore, it seems that this theory has not considered the important role which is played by the affective factors in the process of learning. That is, contrary to the claim made by Newell \& Rosenbloom (1981) concerning the power law of practice, it can be claimed that if the beneficial affective factors are not observed (e.g., in stressed situations), "plotting the logarithm of the time to perform a task against the logarithm of the trial number" (p. 1) does not necessarily yield a straight line. That is, practice does not always make perfect, and one of the prerequisite conditions for the practice to work is what Krashen (1985) has referred to as the "low affective filter".

The other point which should be mentioned is that though Ellis \& Shintani (2013) believe that Skill Acquisition Theory provides a rationale for the strong-interface position, as acknowledged by Ellis (2009), the evidence for all of the three positions (i.e., the noninterface position, the strong interface position, and the weak interface position) is mainly indirect, and they have not been empirically investigated. In fact, this is also the very problem which undermines Skill Acquisition Theory since, as mentioned by Dekeyser (2007b), this theory is under-researched. Dekeyser has attributed this scarcity of research to the methodological problems such as difficulty in gathering large numbers of participants over long periods of time which is usually required for investigating this theory, and also to difficulties in controlling the variables in such studies.

Also, practice emphasized in this theory, as mentioned by Dekeyser (2007a), is effective only for learning similar tasks which does not transfer to dissimilar tasks. Therefore, it can be claimed that this point disregards the creative potentials of human being.

The other criticisms leveled against Skill Acquisition Theory has been put forward by Ellis (2009, as cited in Ellis \& Shintani, 2013) who believes that this theory does not account for two important aspects of SLA. That is, first, it fails to explain the sequence of acquisition. And, second, the idea that the acquisition of all L2 features starts with declarative knowledge is rather far-fetched, since both vocabulary and grammar acquisition in an L2 must involve incidental learning to a great extent and such learning does not need a declarative stage.

\section{Strengths}

At the same time, there are other scholars, who adhering the advantages of the Skill Acquisition Theory, hold views some of which contradict with those of the critics of this theory. For example, Parziale \& Fischer (2009) have discussed how skill theory can be applied in classroom settings.

1) "Skill theory can be used to study development during very short as well as long time periods, and across cognitive, social and language domains." (p. 97)

2) "Skill theory provides a coherent and practical means of defining and identifying the skills and sequences in learning activities." (p. 103)

3) This theory "predicts uneven development, not just across large domains, but even in narrow ones. For example, a student might be able to count a large number of beans from a jar but be unable to count the number of his classmates." (p. 108)

4) "By using a skill theory analysis teachers can begin to understand the effect of support and practice on range of performance. The range of performance observed during lessons that might have been used for many years suddenly can be understood and controlled." (p. 109)

In fact, in spite of the shortcomings leveled against Skill Acquisition Theory, as mentioned by Dekeyser (2007b), this theory fits very well with other aspects of cognitive science. Also, the approach to skill learning has proven to be robust over time, in spite of changes in emphasis, methodology, and terminology. Moreover, the procedure of research in this theory, whether conducted with behavioral data or through neuro-imaging or computer modeling is very explicit, e.g., power curves, computer programs and brain-scanners provides precise answers. Furthermore, research in this field is developmental and rather than providing snapshots of learners it can document learning day after day. Moreover, though research may have less to say about the acquisition order of the language elements in comparison to other more (psycho-) linguistically oriented approaches, but it is explicit and precise regarding the steps that a learner takes during the acquisition of a specific structure. 


\section{CONCLUSION}

Asides from merits and demerits of the Skill Acquisition Theory, there are two issues which highlight the importance of this theory in the field of applied linguistics. The first issue is the relation that exists between this theory and SLA. According to Dekeyser \& Criado (2013), since second/foreign language proficiency involves a set of skills that permit speakers to comprehend and produce messages rapidly and efficiently, cognitive psychology in general and Skill Acquisition Theory, in particular, are also undoubtedly relevant to SLA. For example, one of the attempts to apply this theory to language teaching has been made by Johnson (1996). In the same vein, Chapelle (2009) has discussed the implications of this theory for CALL, believing that it "provides suggestions for learning through practice and for assessment of successful learning" (p. 744). Nevertheless, as acknowledged by Dekeyser (2007b), due to this theory's emphasis on the importance of explicit/declarative knowledge during the initial stages of learning, this theory is most easily applicable to cases where 1) adult learners of high aptitude are involved, 2) the structures to be learned are simple, 3) learners are at fairly early stages of learning, and 4) the context is instructional. The other even more important issue is that this theory does not claim to account for everything about SLA. That is, it does not compete with other theories to acclaim itself as the only valid theory of SLA (Dekeyser, 2007b).

To finalize, it should be mentioned that in spite of these merits, as acknowledged by Ellis (2009), though neurological studies and connectionist models of linguistic knowledge point to the dichotomous nature of explicit and implicit knowledge, there is still controversy over the dichotomous or continuous nature of these two types of knowledge. Considering this point and scarcity of research on the Skill Acquisition Theory in SLA (Dekeyser, 2007b), there is room for more merits or demerits to be revealed in the future.

\section{REFERENCES}

[1] Anderson, J. R. (1982). Acquisition of cognitive skill. Psychological Review, 89(4), 369-406. doi: 10.1037//0033295X.89.4.369

[2] Ackerman, P. L. (1988). Determinants of individual differences during skill acquisition: Cognitive abilities and information processing. Journal of Experimental Psychology: General, 117(3), 288-318. doi: 10.1037//0096-3445.117.3.288

[3] Chapelle, C. A. (2009). The relationship between second language acquisition theory and computer-assisted language learning. The Modern Language Journal, 93, 741-753. doi: 10.1111/j.1540-4781.2009.00970.x

[4] Cohen, J. D., Servan-Schreiber, D., \& McClelland, J. L. (1992). A parallel distributed processing approach to automaticity. American Journal of Psychology, 105(2), 239-269. doi: 10.2307/1423029

[5] Cornford, I. R. (1996). The defining attributes of 'skill' and 'skilled performance': Some implications for training, learning, and program development. Australian and New Zealand Journal of Vocational Education Research, 4(2), 1-25. Retrieved October 30, 2013, from http://www.google.com

[6] DeKeyser, R. M. (2007a). Introduction: Situating the concept of practice. In R. M. DeKeyser (Ed.), Practice in a second language: Perspectives from applied linguistics and cognitive psychology (pp. 1-18). Cambridge: Cambridge University Press.

[7] Dekeyser, R. (2007b). Skill acquisition theory. In B. VanPatten \& J. Williams (Eds.), Theories in second language acquisition: An introduction (pp. 97-113). New Jersey: Lawrence Erlbaum Associates, Inc.

[8] DeKeyser, R. M. (2007c). The future of practice. In R. M. DeKeyser (Ed.), Practice in a second language: Perspectives from applied linguistics and cognitive psychology (pp. 287-304). Cambridge: Cambridge University Press.

[9] Dekeyser, R. M., \& Criado, R. (2013). Automatization, skill acquisition, and practice in second language acquisition. In C. A. Chapelle (Ed.), The encyclopedia of applied linguistics. London: Blackwell.

[10] Ellis, R. (2009). Implicit and explicit learning, knowledge and instruction. In R. Ellis, S. Loewen, C. Elder, R. Erlam, J. Philp, $\&$ H. Reinders (Eds.), Implicit and explicit knowledge in second language learning, testing, and teaching (pp. 3-26). Clevedon: Multilingual Matters.

[11] Ellis, R., \& Shintani, N. (2013). Exploring language pedagogy through second language acquisition research. New York: Routledge.

[12] Gupta, P., \& Dell, G. S. (1999). The emergence of language from serial order and procedural memory. In B. MacWhinney (Ed.), The emergence of language (pp. 447-481). Mahwah, NJ: Erlbaum.

[13] Hulstijn, J. (2002). Towards a unified account of the representation, processing and acquisition of second language knowledge. Second Language Research, 18(3), 193-223. doi: 10.1191/0267658302sr207oa

[14] Johnson, K. (1996). Language teaching and skill learning. Oxford: Blackwell.

[15] Krashen, S. (1985). The input hypothesis: Issues and implications. New York: Longman.

[16] Mystkowska-Wiertelak, A., \& Pawlak, M. (2012). Production-oriented and comprehension-based grammar teaching in the foreign language classroom. New York: Springer.

[17] Newell, A., \& Rosenbloom, P. S. (1981). Mechanisms of skill acquisition and the law of practice. In J. R. Anderson (Ed.), Cognitive skills and their acquisition (pp. 1-55). New Jersey: Erlbaum.

[18] Parziale, J., \& Fischer, K. W. (2009). The practical use of skill theory in classrooms. In R. J. Sternberg \& W. M. Williams (Eds.), Intelligence, instruction, and assessment: Theory into practice ( $\mathrm{pp} .95-110)$. New Jersey: Taylor \& Francis eLibrary.

[19] Pawlak, M. (2011). Instructed acquisition of speaking: Reconciling theory and practice. In M. Pawlak, E. Waniek-Klimczak, \& J. Majer (Eds.), Speaking and instructed foreign language acquisition (pp. 3-23). New York: Multilingual Matters.

[20] Richards, J. C., \& Schmidt, R. (Eds.). (2010). Longman dictionary of language teaching and applied linguistics. Harlow: Pearson Education Ltd.

[21] Speelman, C. (2005). Skill acquisition: History, questions, and theories. In C. Speelman \& K. Kinser (Eds.), Beyond the learning curve: The construction of mind (pp. 26-64). Oxford: Oxford University Press. 
[22] Taatgen, N. A. (2002). A model of individual differences in skill acquisition in the Kanfer-Ackerman air traffic control task. Cognitive Systems Research, 3, 103-112. Retrieved October 30, 2013, from http://www.ai.rug.nl/ niels/publications/CSRpublished.pdf

[23] Trofimovich, P., \& McDonough, K. (2013). Priming. In P. Robinson (Ed.), The Routledge encyclopedia of second language acquisition (pp. 505-508). New York: Routledge.

[24] Truscott, J. \& Sharwood Smith, M. (2004). Acquisition by processing: A modular perspective on language development. Bilingualism: Language and Cognition, 7(1),1-20. doi: 10.1017/S1366728904001178

[25] Vanpatten, B., \& Benati, A. G. (2010). Key terms in second language acquisition. New York: Continuum International Publishing Group.

[26] VanPatten, B., \& Williams, J. (2007). Preface. In B. VanPatten \& J. Williams (Eds.), Theories in second language acquisition: An introduction (pp. vii-viii). Cambridge: Cambridge University Press.

Masumeh Taie is currently a PhD candidate of TEFL at Islamic Azad University, Science and Research Branch, Tehran, Iran. She has taught technical English courses to the students of medicine at Iran university of Medical Sciences, and different English courses at Islamic Azad University, Medical Branch of Tehran for more than five years. Her research interests are critical thinking, ESP, and educational philosophy. 